\title{
Age-Dependent Effects of Indomethacin on Hypoxic Vasoconstriction in Neonatal Lamb Lungs
}

\author{
JOHN B. GORDON, MARY L. TOD, RANDALL C. WETZEL, MARY L. MCGEADY, \\ N. FRANKLIN ADKINSON, JR., AND J. T. SYLVESTER \\ Departments of Anesthesiology/Critical Care Medicine and Medicine, The Johns Hopkins Medical Institutions at \\ the Francis Scott Key Medical Center, Baltimore, Maryland 21224
}

\begin{abstract}
Although smooth muscle is abundant in the pulmonary vessels of young animals at birth, it is not clear if these vessels respond more vigorously to hypoxia than the less muscular vessels of older neonates. To determine the effect of age on the pulmonary vascular response to hypoxia during the neonatal period in a single species, we measured the steady-state stimulus-response relationship between inspired oxygen tension $(200,50,30$ and $0 \mathrm{~mm}$ $\mathrm{Hg}$ ) and pulmonary artery pressure-flow curves in isolated blood perfused lungs from 2- to 4- and 12- to 14-day-old lambs. Hypoxic vasoconstriction was attenuated in the younger newborns at an inspired oxygen tension of $50 \mathrm{~mm}$ $\mathrm{Hg}$, but not at the other oxygen tensions. To determine if this age-related difference was due to differences in modulation of hypoxic vasoconstriction by cyclooxygenase products, we assayed the metabolite of prostacyclin, 6keto-prostaglandin $F_{1 \alpha}$ in the perfusate and determined the effects of indomethacin $(40 \mu \mathrm{g} / \mathrm{ml})$ on the hypoxic stimulusresponse relationship. There was no age-related difference in perfusate concentration of 6-keto-prostaglandin $F_{1 \alpha}$ at any oxygen tension. However, indomethacin reversed the age-dependent attenuation of hypoxic vasoconstriction at inspired oxygen tension $=50 \mathrm{~mm} \mathrm{Hg}$ such that in indomethacin-treated lungs pulmonary vasomotor tone was higher in 2- to 4-day-old lungs than in 12- to 14-day-old lungs. This marked enhancement of hypoxic reactivity by indomethacin in the younger lambs suggests that in isolated neonatal lamb lungs cyclooxygenase products exerted a vasodilatory modulation of hypoxic vasoconstriction that decreased with age. (Pediatr Res 23: 580-584, 1988)
\end{abstract}

\section{Abbreviations}

6-keto-PGF $F_{1 \alpha}, 6$-keto-prostaglandin $\mathrm{F}_{1 \alpha}$ PVR, pulmonary vascular resistance

HPV, hypoxic pulmonary vasoconstriction

PG, prostaglandin

Ppa, pulmonary arterial pressure

PGI $_{2}$, prostacyclin

LT, leukotriene

$\mathbf{P} / \mathbf{Q}$ curves, pressure-flow curves

$\mathrm{PiO}_{2}$, inspired oxygen tension

$\dot{\mathrm{Q}}$, constant flow

Received May 11, 1987; accepted February 1, 1988.

Correspondence Dr. John B. Gordon, Room D-983, The Montreal Children's Hospital, 2300 Tupper Street, Montreal, Quebec, Canada H3H 1P3.

Supported in part by NIH Grant HL 01342 and in part by a grant-in-aid from the American Heart Association with funds contributed in part from the Heart Association of Central Maryland.
PVR decreases dramatically when ventilation is initiated at birth (1-7). This is likely a consequence of mechanical distention of the lung $(1,2)$, increased oxygen tension $(1,2)$, and release of dilator PG (2-6). Subsequent decreases in normoxic PVR have been well documented in the growing piglet (7) and in other species $(2,8,9)$. In contrast, age-related changes in HPV are less clear. It has been suggested that the extent of arteriolar muscularization determines the vigor of HPV (10-12). In this case, the newborn animal with its highly muscularized vessels $(2,7,9,10)$ should have a more vigorous hypoxic response than the older animal. Although some studies show an age-dependent decrease in $\operatorname{HPV}(8,13)$, others report an increase with age $(10,14,15)$.

One possible explanation for these apparently conflicting results is that the vigor of HPV may be influenced by factors other than vascular muscularization. For instance, there could be agedependent differences in the modulation of HPV by pulmonary vasodilators. Although vasodilators such as $\mathrm{PGI}_{2}$ are released during HPV in both young neonates and mature animals (16, 17 ), the action and metabolism of various $P G$ may vary with age $(18,19)$. For example, the vasodilator $\mathrm{PGE}_{2}(20)$ is more slowly metabolized in the neonate (18). $\mathrm{PGD}_{2}$ is a pulmonary vasodilator in neonatal lambs, but a vasoconstrictor in older animals (21-23). Such differences may be partially responsible for the variable effects of cyclooxygenase inhibition on the developing pulmonary vasculature. In the intact pig, meclofenamate increased normoxic PVR at 5-12 days of age, but had no effect between 13 and 88 days of age (24). Despite this age-related difference, meclofenamate did not alter HPV in either age group and there was no effect of age on HPV (24). In goats, indomethacin-enhanced normoxic PVR in perfused left lower lobes of both premature and mature newborns; however, in this species HPV was potentiated in both age groups (25). In isolated perfused lungs from 2- to 3-month-old lambs, however, there was no effect of indomethacin on steady-state pulmonary pressures during graded hypoxia $(26,27)$.

The purpose of our study was 2-fold: first to determine if the pulmonary vascular response to hypoxia changed during the neonatal period in a single species, the sheep, and second, to determine if HPV in this species was modulated by dilator PG in an age-dependent fashion.

\section{METHODS}

Pulmonary vasomotor responses to four levels of $\mathrm{PiO}_{2}$ were determined in isolated lungs of 2- to $4-(n=12)$ and 12 - to 14$(n=12)$ day-old lambs perfused in situ. In half of the lungs, indomethacin $(40 \mu \mathrm{g} / \mathrm{ml}$ perfusate) was added to the reservoir before perfusion was initiated. This amount of indomethacin has previously been shown to inhibit cyclooxygenase activity (26, 27). 
This preparation was only slightly modified from that used previously for the study of older animals (26-28). Briefly, lambs were anesthetized with ketamine $(50 \mathrm{mg} / \mathrm{kg}$, intramuscular) and supplemental oxygen was provided by a loose-fitting mask. Femoral venous and arterial catheters were inserted and a tracheotomy performed. Pancuronium bromide $(0.1 \mathrm{mg} / \mathrm{kg}$, intravenous $)$ was administered and ventilation with a warm, humidified hyperoxic gas mixture was initiated with an animal ventilator (Harvard, model 613) at a tidal volume of $15 \mathrm{ml} / \mathrm{kg}$, rate of $10 /$ min and end-expiratory pressure of $4 \mathrm{~mm} \mathrm{Hg}$. Heparin (3000$5000 \mathrm{U}$, intravenous) was administered and the lamb was exsanguinated rapidly via the femoral artery catheter. As exsanguination progressed, the gas mixture was adjusted to $5.4 \% \mathrm{CO}_{2}, 28 \%$ $\mathrm{O}_{2}$, and balance $\mathrm{N}_{2}$. A median sternotomy was performed and the ductus arteriosus ligated in all animals. When exsanguination was completed (about $5 \mathrm{~min}$ ), the left atrium and pulmonary artery were cannulated and perfusion was initiated with a mixture of autologous blood and 3\% Dextran-70 in Ringer's lactate (hematocrit 16-20\%). The time of pulmonary ischemia was 12$17 \mathrm{~min}$.

The perfusate was pumped (Sarns, model 3500) from a reservoir at a $\dot{Q}$ of $50 \mathrm{ml} / \mathrm{kg} \cdot \mathrm{min}$ (all weights refer to body weight) through a heat exchanger (Travenol Miniprime Pediatric), bubble trap/filter, and flow probe (Carolina Medical Instruments, model EP300A) into the pulmonary artery. Perfusate drained from the left atrium to the reservoir that was held below the level of the lungs to ensure subatmospheric pulmonary venous pressure. During perfusion, we noted retrograde flow of the perfusate from the pulmonary circulation to the aorta, presumably via the bronchial artery. This anastomotic flow was returned to the reservoir via the femoral artery catheter previously inserted into the thoracic aorta for exsanguination of the lamb.

Ppa, left atrial, and tracheal pressures (Statham transducer models P50 and PM5E), as well as flow (Carolina Medical Instruments Flowmeter, model 501), and inspired $\mathrm{O}_{2}$ and $\mathrm{CO}_{2}$ tensions (Beckman OM11, LB2) were constantly measured and recorded (Grass Polygraph, model 7). At the beginning of perfusion, and at each $\mathrm{PiO}_{2}$ during the experiment, perfusate blood gases (Radiometer BMS3 MK2), hematocrit, and glucose concentrations (Dextrostix) were determined. The pH was maintained in a normal range by the addition of $1 \mathrm{M} \mathrm{NaHCO}_{3}$. Glucose concentration was maintained between 90 and $130 \mathrm{mg} /$ $100 \mathrm{ml}$ by addition of $50 \%$ glucose in water.

After a 40 -min stabilization period $\left(\mathrm{PiO}_{2}=200 \mathrm{~mm} \mathrm{Hg}, \mathrm{PiCO}_{2}\right.$ $=38 \mathrm{~mm} \mathrm{Hg}$ ), the first hypoxic challenge was begun. To avoid time or order-dependent effects, each preparation within a group was exposed to a different order of hypoxic challenges $\left(\mathrm{PiO}_{2}=\right.$ 50,30 , and $0 \mathrm{~mm} \mathrm{Hg}$ ) with a return to $\mathrm{PiO}_{2}=200 \mathrm{~mm} \mathrm{Hg}$ after each hypoxic challenge. After a $10-\mathrm{min}$ stabilization period at each $\mathrm{PiO}_{2}, \mathrm{P} / \mathrm{Q}$ curves were determined. The ventilator was turned off at end expiration (tracheal pressure $=4 \mathrm{~mm} \mathrm{Hg}$ ), a stand-pipe in the system was opened and filled by increasing flow to $150 \mathrm{ml} / \mathrm{kg} \cdot \mathrm{min}$. After Ppa had stabilized (about $10 \mathrm{~s}$ ), the pump was turned off and the stand-pipe allowed to empty across the pulmonary vasculature while Ppa and $\dot{Q}$ were recorded on an X-Y plotter (Hewlett Packard, model 7044A). The stand-pipe was then closed, ventilation and perfusion resumed, and the lungs hyperinflated. These $\mathrm{P} / \dot{\mathrm{Q}}$ curves were measured every 5 min until two consecutive curves fell within $1 \mathrm{~mm} \mathrm{Hg}$ of each other at $\dot{\mathrm{Q}}=50 \mathrm{ml} / \mathrm{kg} \cdot \min \left(\mathrm{Ppa}_{50}\right)$, defining the steady-state response to that $\mathrm{PiO}_{2}$. The next $\mathrm{PiO}_{2}$ was then administered and the process repeated until all six exposures were completed.

At each $\mathrm{PiO}_{2}$ the Ppa at flow $=10,30,50,70,90$, and 110 $\mathrm{ml} / \mathrm{kg} \cdot \mathrm{min}$ were determined from the $\mathrm{P} / \dot{\mathrm{Q}}$ recording obtained when the steady-state response had occurred. This permitted determination of mean $\mathrm{P} / \dot{\mathrm{Q}}$ curves at each $\mathrm{PiO}_{2}$. The curves measured during the three exposures to an $\mathrm{O}_{2}$ tension of 200 $\mathrm{mm} \mathrm{Hg}$ were averaged in each preparation. The Ppa at flows $=$ 0,130 , and $150 \mathrm{ml} / \mathrm{kg} \cdot \mathrm{min}$ were not included because of the noise of the pulmonary artery signal immediately after stopping the pump (flow $=150$ and $130 \mathrm{ml} / \mathrm{kg} \cdot \mathrm{min}$ ) and the difficulty in determining the exact pressure at zero flow.

At 40 min and after each steady-state response had occurred, a sample of perfusate $(4.5 \mathrm{ml})$ was collected for PG analysis in tubes containing $5 \mathrm{~g}$ of indomethacin and $7.2 \mathrm{mg}$ of EDTA. After centrifugation, the supernatant was stored at $-16^{\circ} \mathrm{C}$ until radioimmunoassay for 6 -keto-PGF - $_{1 \alpha}$ was performed as previously described $(26,27)$.

All results are expressed as means $\pm 1 \mathrm{SE}$. The differences in effects of graded hypoxia on the $\mathrm{P} / \mathrm{Q}$ curves and on concentrations of 6-keto-PGF $F_{1 \alpha}$ among groups were compared by splitplot design analysis of variance. Other characteristics of each group were compared by one-way analysis of variance (29). Differences were considered significant when $p \leq 0.05$.

\section{RESULTS}

There were no differences between groups in terms of mean hematocrit $(16-20 \%)$, mean perfusate temperature $\left(37.8-38.5^{\circ}\right.$ C), tidal volume $(15 \mathrm{ml} / \mathrm{kg}$ body weight), ventilator rate $(10 /$ $\mathrm{min})$, peak or end-expiratory tracheal pressures (10-12 and 4 $\mathrm{mm} \mathrm{Hg}$, respectively) or duration of the study (190-212 min). The mean weight of the older lambs $(8.0 \pm 0.7 \mathrm{~kg})$ was greater than that of the younger $(5.0 \pm 0.05 \mathrm{~kg})$. Perfusate $\mathrm{PO}_{2}, \mathrm{PCO}_{2}$, and $\mathrm{pH}$ did not differ between groups at any $\mathrm{PiO}_{2}$ (Table 1).

The $\mathrm{P} / \mathrm{Q}$ relationships measured at different inspired $\mathrm{O}_{2}$ tensions in the 2- to 4- and 12- to 14-day-old lambs are shown in Figure 1. Three-way analysis of variance (age, $\mathrm{PiO}_{2}$, and $\left.\dot{\mathrm{Q}}\right)$ of these data revealed a significant effect of age $(p<0.01)$ on the stimulus-response relationship between $\mathrm{PiO}_{2}$ and the $\mathrm{P} / \mathrm{Q}$ curves. To facilitate comparisons between ages, we quantified the response at each $\mathrm{PiO}_{2}$ by measuring pulmonary artery pressure at a flow of $50 \mathrm{ml} / \mathrm{kg} \cdot \mathrm{min}\left(\mathrm{Ppa}_{50}\right)$. Figure 2 shows the stimulusresponse relationship between $\mathrm{PiO}_{2}$ and $\mathrm{Ppa}_{50}$ measured directly from individual $P / Q$ curves in both age groups. In both groups, mean $\mathrm{Ppa}_{50}$ increased as the $\mathrm{PiO}_{2}$ was decreased from 200 to 30 $\mathrm{mm} \mathrm{Hg}$. Further decreases in $\mathrm{PiO}_{2}$ below $30 \mathrm{~mm} \mathrm{Hg}$ caused the $\mathrm{Ppa}_{50}$ to fall. This biphasic curve is similar to that reported in the pig, ferret, cat, rabbit, and older lambs $(27,28)$. The only difference between the two age groups was observed at a $\mathrm{PiO}_{2}$ of $50 \mathrm{~mm} \mathrm{Hg}$, where the response was less in younger lambs.

The $\mathrm{P} / \mathrm{Q}$ curves measured at each $\mathrm{PiO}_{2}$ in lungs treated with indomethacin were also analyzed by three-way analysis of variance. As in the control lungs, there was a significant effect of age $(p<0.05)$ on the stimulus-response relationship between $\mathrm{PiO}_{2}$

Table 1. Perfusate gases at each $\mathrm{PiO}_{2}(\text { mean } \pm S E)^{*}$

\begin{tabular}{|c|c|c|c|c|c|c|}
\hline \multirow[b]{2}{*}{ Age (day) } & \multicolumn{4}{|c|}{$\mathrm{PO}_{2}$ at $\mathrm{PiO}_{2}(\mathrm{~mm} \mathrm{Hg})$} & \multirow[b]{2}{*}{$\mathrm{pH}$ (mean) } & \multirow[b]{2}{*}{$\mathrm{PCO}_{2}$ (mean) } \\
\hline & 200 & 50 & 30 & 0 & & \\
\hline $2-4$ & $138.2 \pm 2.5$ & $44.0 \pm 1.7$ & $27.7 \pm 2.2$ & $3.3 \pm 2.4$ & $7.39 \pm 0.01$ & $28.8 \pm 1.1$ \\
\hline 2-4 (inde) & $134.7 \pm 5.1$ & $41.5 \pm 2.4$ & $25.0 \pm 1.1$ & $4.2 \pm 2.0$ & $7.39 \pm 0.004$ & $28.9 \pm 0.7$ \\
\hline $12-14$ & $122.3 \pm 7.2$ & $37.7 \pm 1.9$ & $22.2 \pm 1.3$ & $1.8 \pm 1.8$ & $7.39 \pm 0.01$ & $29.1 \pm 1.0$ \\
\hline 12-14 (indo) & $139.5 \pm 6.5$ & $42.5 \pm 2.1$ & $25.0 \pm 1.1$ & $4.6 \pm 2.2$ & $7.38 \pm 0.01$ & $28.6 \pm 0.7$ \\
\hline
\end{tabular}

* The perfusate $\mathrm{PO}_{2}$ at each $\mathrm{PiO}_{2}$ as well as mean $\mathrm{pH}$ and $\mathrm{PCO}_{2}$ are shown for each group. Only the effects of $\mathrm{PO}_{2}$ were significant within groups. There were no differences between groups. 
A



B

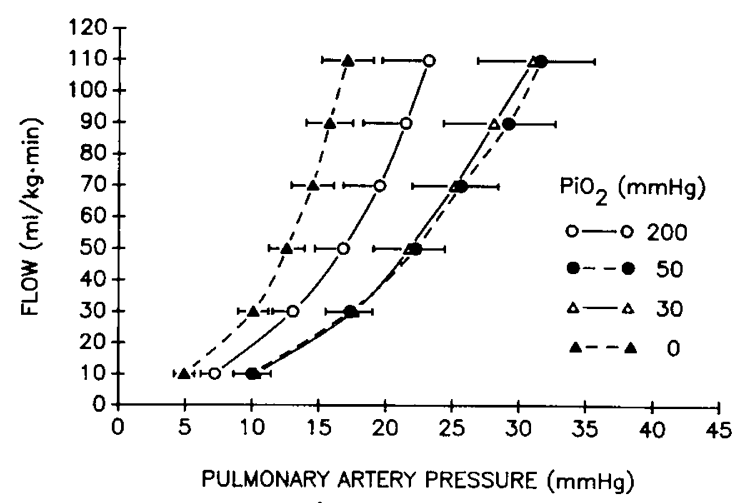

Fig. 1. Effects of age on $\mathrm{P} / \mathrm{Q}$ curves in response to different levels of $\mathrm{PiO}_{2}$. P/Q curves for control lungs from 2- to 4-day-old $(A)$ and 12- to 14-day-old $(B)$ lambs are shown at four different inspired $\mathrm{O}_{2}$ tensions $\left(\mathrm{PiO}_{2}=200,50,30,0 \mathrm{~mm} \mathrm{Hg}\right)$.

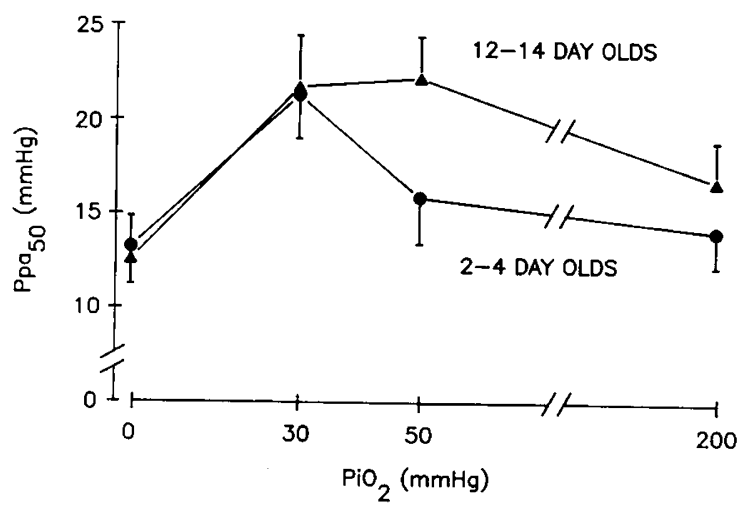

Fig. 2. Stimulus-response relationships between $\mathrm{PiO}_{2}$ and $\mathrm{Ppa}_{50}$. Mean stimulus-response relationships for 2- to 4- and 12- to 14-day-old lambs are shown.

and the $\mathrm{P} / \mathrm{Q}$ curves. To determine whether there was an agedependent effect of indomethacin on hypoxic vasoconstriction, we compared $\mathrm{P} / \dot{\mathrm{Q}}$ curves from control and treated lungs at each $\mathrm{PiO}_{2}$ (Fig. 3). At $\mathrm{PiO}_{2}=200 \mathrm{~mm} \mathrm{Hg}$ (Fig. 3A), there were no differences due to age or indomethacin. At $\mathrm{PiO}_{2}=50 \mathrm{~mm} \mathrm{Hg}$ (Fig. $3 B$ ), indomethacin had no effect in 12- to 14-day-old lambs, but markedly enhanced vasoconstriction (i.e. shifted the $\mathrm{P} / \dot{\mathrm{Q}}$ curve to higher pressures) in the 2- to 4-day-old lambs. This marked effect reversed the influence of age: vasoconstriction was enhanced by increasing age in control lungs but diminished by increasing age in indomethacin-treated lungs. This striking reversal of the effects of age by indomethacin was not observed at other levels of $\mathrm{O}_{2}$. At $\mathrm{PiO}_{2}=30 \mathrm{~mm} \mathrm{Hg}$ (Fig. $3 C$ ), there was no effect of age; however, indomethacin enhanced vasoconstriction by equal amounts in each age group. At $\mathrm{PiO}_{2}=0 \mathrm{~mm} \mathrm{Hg}$ (Fig. $3 D$ ), both indomethacin and age independently altered the $\mathrm{P} / \mathrm{Q}$ curves but the analysis of variance revealed that the effects of indomethacin were not altered by age.

The mean perfusate concentrations of 6-keto-PGF ${ }_{1 \alpha}$, the stable hydrolysis product of $\mathrm{PGI}_{2}$, were not different in the control lungs of 2- to 4- as compared to 12- to 14-day-old sheep (Table 2). Furthermore, there was no significant change in concentration of 6-keto-PGF $\mathrm{PG}_{1 \alpha}$ with hypoxia in either age group. The addition of indomethacin markedly reduced the concentration at both ages $(p<0.001)$, indicating effective cyclooxygenase inhibition.For example, the concentrations of 6-keto-PGF ${ }_{1 \alpha}$ measured at the end of perfusion of indomethacin-treated lungs were 0.9 \pm 0.1 and $1.3 \pm 0.2 \mathrm{ng} / \mathrm{ml}$ at $2-4$ and $12-14$ days of age, respectively.

\section{DISCUSSION}

The developmental aspects of HPV have been studied using a variety of species, ages, and methods. These studies have yielded differing results $(8,10,13-15,24)$. Rendas et al. (10) described an increase in hypoxic reactivity in intact piglets between 2-4 wk and 6 months and correlated this with peripheral extension of arterial smooth muscle to the acinar level. Owen-Thomas and Reeves (14) reported an increase in HPV between 1 and 9-11 days in isolated pump-perfused lungs of rabbits. Recently Fike and Hansen (15) have extended this finding to show an increase in HPV between 3-8 and 10-14 days in isolated rabbit lungs. In contrast, Reeves and Leathers (8) observed a decrease in hypoxic pulmonary artery pressure in intact growing calves. By measuring the diversion of flow from the hypoxic to the normoxic lung in sheep, Custer and Hales (13) concluded that HPV was more vigorous at 3-21 days than at 2-3 yr of age. Finally, Redding et al. (24) found no developmental differences in HPV in intact piglets at 5-12 and 13-88 days of age. Herein we found a significant effect of age on the relationship between $\mathrm{PiO}_{2}$ and the pulmonary vascular $\mathrm{P} / \mathrm{Q}$ curve (Fig. 1). This difference was observed at $\mathrm{PiO}_{2}=50 \mathrm{~mm} \mathrm{Hg}$ where the hypoxic vasoconstrictor response in lungs from 2- to 4-day-old lambs was less than that of lungs from 12- to 14-day-old lambs (Fig. 2). Thus, our results suggest that there is an increase in hypoxic reactivity with age, in agreement with those reported in isolated rabbit lungs (14, 15).

There are several potential reasons for the apparent differences between our results and those of others who did not find that HPV increased with age. Clearly, the extrapulmonary neuroendocrine modulation of pulmonary vasomotor tone in intact animals could explain the difference between intact and isolated preparations such as ours. Differences in species may also be important. For example, comparable developmental stages occur at different ages in different species (7). The level of oxygen tension used as a stimulus for HPV has varied. As demonstrated by our results, we could have reached a different conclusion had we studied but one level of $\mathrm{PiO}_{2} ;$ e.g. $30 \mathrm{~mm} \mathrm{Hg}$, where no differences were found. Finally, we measured the resistive characteristics of the pulmonary vasculature by $\mathrm{P} / \dot{\mathrm{Q}}$ curves generated over a wide range of flows when the response to hypoxia had attained a steady-state. Relative to other studies, this approach may have eliminated potential inaccuracies resulting from insufficient time to allow a complete hypoxic response to develop, as well as from using simply the ratio of pressure to flow or pressure at constant flow to quantify the pulmonary vascular response (30).

In many species medial muscle thickness of pulmonary arterioles is greatest immediately postnatally $(7,31,32)$. The medial 

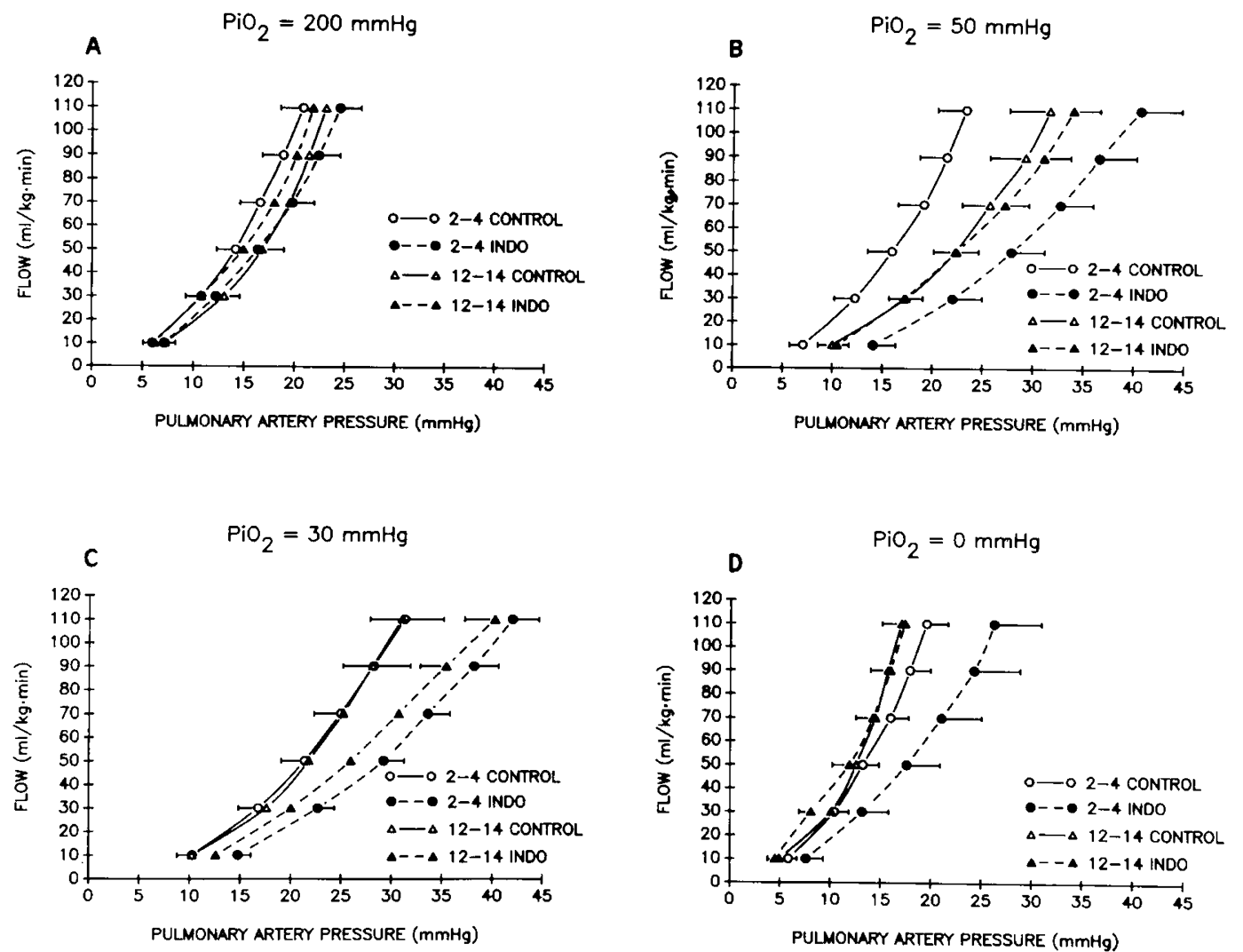

Fig. 3. Interaction of age and indomethacin on $\mathrm{P} / \mathrm{Q}$ curves at each $\mathrm{PiO}_{2} . \mathrm{P} / \mathrm{Q}$ curves for control and indomethacin-treated lungs at both ages are PEDIATRIC RESEARCH

Vol. 23, No. 6, 1988

Table 2. Perfusate concentration of 6-keto- $P G F_{1 \alpha}(\mathrm{ng} / \mathrm{ml})($ mean

\begin{tabular}{ccccc}
\multicolumn{5}{c}{ $\pm S E)$} \\
\cline { 2 - 5 } Age (day) & 200 & 50 & 30 & 0 \\
\hline $2-4$ & $15.3 \pm 4.4$ & $19.1 \pm 6.2$ & $16.6 \pm 5.4$ & $14.3 \pm 6.2$ \\
$12-14$ & $18.0 \pm 5.8$ & $14.6 \pm 5.5$ & $22.4 \pm 8.9$ & $16.0 \pm 8.8$ \\
\hline
\end{tabular}

* The values at each $\mathrm{PiO}_{2}$ are shown for control groups at each age.

muscularization of these arterioles has been shown to involute with age. Inasmuch as vascular responsiveness to hypoxia among species has been related to the degree of vascular muscularization (11), this suggests that HPV should be greater in younger animals. If the pulmonary vasculature of sheep undergoes the same involution seen in other species, then some mechanism other than muscularization is required to explain why HPV was depressed in the isolated lungs of our younger lambs.

Many studies suggest that dilator PG may contribute to the normally low PVR occurring during normoxia and may modulate $\operatorname{HPV}(6,16,17,24,25,33-35)$. Potent prostanoid vasodilators, which contribute to the decrease in PVR after birth (36 ), modulate the hypoxic pressor response in older animals of several species $(17,33-35)$. Tyler et al. (25) observed potentiation of HPV by indomethacin in isolated perfused left lower lobes of perinatal goats. This potentiation may have been greater in lungs of premature newborns than in lungs of mature newborns (25). In contrast, Redding et al. (24) did not observe an age-related difference in HPV in intact piglets either before or after meclofenamate. However, they found that meclofenamate significantly increased normoxic PVR in piglets 5-12 days old, but had no effect in older piglets. Our results showed that indomethacin markedly diminished perfusate 6-keto-PGF ${ }_{1 \alpha}$ levels, indicating effective blockade of cyclooxygenase, and enhanced $\mathrm{HPV}$ at $\mathrm{PiO}_{2}$ $=30$ and $50 \mathrm{~mm} \mathrm{Hg}$ (Fig. $3 B$ and $C$ ); however, indomethacin altered the effect of age only at a $\mathrm{PiO}_{2}$ of $50 \mathrm{~mm} \mathrm{Hg}$. At this $\mathrm{PiO}_{2}$, indomethacin reversed the age-related increase in HPV seen in control lungs, such that in indomethacin-treated lungs the $\mathrm{P} / \mathrm{Q}$ curve in 2- to 4-day-old lambs was shifted to the right of the curve in older lambs (Fig. $3 B$ ). These results suggest that at a $\mathrm{PiO}_{2}$ of $50 \mathrm{~mm} \mathrm{Hg}$ dilator $\mathrm{PG}$ modulated $\mathrm{HPV}$ to a greater extent in younger lambs.

Inasmuch as prostacyclin is a potent pulmonary vasodilator reported to modulate the hypoxic response in other species (17, 33-35), we assayed perfusate samples for 6-keto-PGF ${ }_{1 \alpha}$, the stable metabolite of $\mathrm{PGI}_{2}$. The concentrations of 6-keto-PGF ${ }_{1 \alpha}$ were not different in the two age groups at any level of $\mathrm{O}_{2}$ (Table 2). Despite this, prostacyclin could still be responsible for an agedependent effect of indomethacin if the response of the pulmonary vasculature to $\mathrm{PGI}_{2}$ varied with age in a fashion analagous to responses to arachidonic acid (36) and $\mathrm{PGF}_{2 \alpha}$ (37). At comparable doses of arachidonic acid, newborn lambs showed a greater increase in PVR than in ventilaged fetal lambs (36). Also, mature newborn goats were more sensitive to $\mathrm{PGF}_{2 \alpha}$ than premature newborn goats (37).

Another possible mechanism to explain the age-dependent effects of indomethacin is the formation of a dilator PG other than $\mathrm{PGI}_{2}$. Both $\mathrm{PGE}_{2}$ and $\mathrm{PGD}_{2}$ cause pulmonary vasodilation in the newborn lamb $(20,22,23)$. In addition, pulmonary PGE $_{2}$ catabolism is low at birth in lambs, but rapidly increases with age (18). Age-dependent differences in the concentration of either of these agents may have contributed to our results. Alternatively, there may have been age-related effects of indomethacin not due to inhibition of cyclooxygenase. For example, indomethacin may divert arachidonic acid to the lipoxygenase pathway leading to the production of potent vasoconstrictor LT (38). Although $\mathrm{LTD}_{4}$ is a potent pulmonary vasoconstrictor in newborn lambs (39), this explanation seems unlikely because 1) cyclooxygenase inhibition blunted the constrictor response to $\mathrm{LTD}_{4}$ in adult sheep (40) and 2) indomethacin inhibited the pulmonary pressor response to arachidonic acid in adult sheep (41) and perinatal 
lambs (36). Other nonspecific effects of indomethacin are possible $(42,43)$. However, as indomethacin is $90 \%$ protein bound, the free indomethacin concentration in the perfusate was estimated to be $3-5 \mu \mathrm{g} / \mathrm{ml}$. At this concentration, indomethacin is thought to act relatively specifically as a cyclooxygenase inhibitor $(42,43)$.

In summary, we found that the pulmonary vascular response to an inspired oxygen tension of $50 \mathrm{~mm} \mathrm{Hg}$, but not 30 or $0 \mathrm{~mm}$ $\mathrm{Hg}$, increased with age in isolated lungs from neonatal lambs. This age-dependent effect was reversed by indomethacin. These data suggest that at $\mathrm{PiO}_{2}=50 \mathrm{~mm} \mathrm{Hg}$ dilator prostaglandins modulated HPV to a greater extent in 2- to 4-day-old lambs than in 12- to 14-day-old lambs.

Acknowledgments. The authors thank Mrs. Nancy Martin, Mrs. Sylvie Lapointe, Ms. Elaine Sherman, and Mrs. Diane Blueford for secretarial assistance with this manuscript, and Teresa Privett for the illustrations.

\section{REFERENCES}

1. Cassin S, Dawes GS, Mott JC, Ross BB, Strang LB 1964 The vascular resistance of the foetal and newly ventilated lung of the lamb. J Physiol 171:61-79

2. Rudolph AM 1979 Fetal and neonatal pulmonary circulation. Annu Rev Physiol 41:383-395

3. Cassin S 1980 Role of prostaglandins and thromboxanes in the control of the pulmonary circulation in the fetus and newborn. Semin Perinatol 4:101107

4. Leffler CW, Tyler TL, Cassin S 1978 Effect of indomethacin on pulmonary vascular response to ventilation of fetal goats. Am J Physiol 234:H346-H351

5. Hammerman C, Scarpelli EM 1984 Indomethacin and the cardiopulmonary adaptations of transition. Pediatr Res 18:842-845

6. Leffler CW, Hessler JR, Green RS 1984 The onset of breathing at birth stimulates pulmonary vascular prostacyclin synthesis. Pediatr Res 18:938942

7. Haworth SG, Hislop AA 1981 Adaptation of the pulmonary circulation to extra-uterine life in the pig and its relevance to the human infant. Cardiovas Res 15:108-119

8. Reeves JT, Leathers JE 1964 Circulatory changes following birth of the calf and the effect of hypoxia. Circ Res 15:343-354

9. Rudolph AM 1980 High pulmonary vascular resistance after birth. Clin Pediatr 19:585-590

10. Rendas A, Branthwaite M, Lennox S, Reid L 1982 Response of the pulmonary circulation to acute hypoxia in the growing pig. J Appl Physiol 52:811-814

11. Tucker A, McMurtry IF, Reeves JT, Alexander AF, Will DH, Grover RF 1975 Lung vascular smooth muscle as a determinant of pulmonary hypertension at high altitude. Am J Physiol 228:762-767

12. Rabinovitch M, Gamble W, Nadas AS, Miettinen OS, Reid L 1979 Rat pulmonary circulation after chronic hypoxia: hemodynamic and structural features. Am J Physiol 236:H818-H827

13. Custer JR, Hales CA 1985 Influence of alveolar oxygen on pulmonary vasoconstriction in newborn lambs versus sheep. Am Rev Respir Dis 132:326331

14. Owen-Thomas JB, Reeves JT 1969 Hypoxia and pulmonary arterial pressure in the rabbit. J Physiol 201:665-672

15. Fike CD, Hansen TN 1987 Hypoxic vasoconstriction increases with postnatal age in lungs from newborn rabbits. Circ Res 60:297-303

16. Green RS, Leffler CW 1984 Hypoxia stimulates prostacyclin synthesis by neonatal lungs. Pediatr Res 18:832-835

17. Voelkel NF, Gerber JG, McMurtry IF, Nies AS, Reeves JT 1981 Release of vasodilator prostaglandin, $\mathrm{PGI}_{2}$, from isolated rat lung during vasoconstriction. Circ Res 48:207-213

18. Printz MP, Skidgel RA, Friedman WF 1984 Studies of pulmonary prostaglandin biosynthetic and catabolic enzymes as factors in ductus arteriosus patency and closure. Evidence for a shift in products with gestational age. Pediatr Res 18:19-24

19. Simberg N, Uotila P 1983 The metabolism of arachidonic acid in isolated perfused fetal and neonatal rabbit lungs. Prostaglandins 25:629-638

20. Cassin S, Tyler T, Leffler C, Wallis R 1979 Pulmonary and systemic vascular responses of perinatal goats to prostaglandins $E_{1}$ and $E_{2}$. Am $J$ Physiol 236:H828-H832

21. Lock JE, Olley PM, Coceani F 1980 Direct pulmonary vascular responses to prostaglandins in the conscious newborn lamb. Am J Physiol 238:H631H638

22. Philips III JB, Lyrene RK, McDevitt M, Perlis W, Satterwhite C, Cassady G 1983 Prostaglandin $\mathrm{D}_{2}$ inhibits hypoxic pulmonary vasoconstriction in neonatal lambs. J Appl Physiol 54:1585-1589

23. Cassin S, Tod M, Philips J, Frisinger J, Jordan J, Gibbs C 1981 Effects of prostaglandin $\mathrm{D}_{2}$ on perinatal circulation. Am J Physiol 240:H755-H760

24. Redding GJ, McMurtry I, Reeves JT 1984 Effects of meclofenamate on pulmonary vascular resistance correlate with postnatal age in young piglets. Pediatr Res 18:579-583

25. Tyler T, Wallis R, Leffler C, Cassin S 1975 The effects of indomethacin on the pulmonary vascular response to hypoxia in the premature and mature newborn goat. Proc Soc Exp Biol Med 150:695-698

26. Wetzel RC, Gordon JB, Gregory TJ, Gioia FR, Adkinson NF Jr, Sylvester JT 1985 High-frequency ventilation attenuation of hypoxic pulmonary vasoconstriction. Am Rev Respir Dis 132:99-103

27. Gordon JB, Wetzel RC, McGeady ML, Adkinson NF Jr, Sylvester JT 1986 Effects of indomethacin on estradiol-induced attenuation of hypoxic vasoconstriction in lamb lungs. J Appl Physiol 61:2116-2121

28. Peake MD, Harabin AL, Brennan AJ, Sylvester JT 1981 Steady-state vascular responses to graded hypoxia in isolated lungs of five species. $J$ Appl Physiol 51:1214-1219

29. Kirk RE 1968 Split plot design. Factoral design with block treatment confounding. In: Belmont CA (ed) Experimental Design, Procedures of the Behavioral Sciences. Brookes-Cole, Belmont, CA, pp 245-318

30. Mitzner W, Huang I 1987 Interpretation of pressure-flow curves in the pulmonary vascular bed. In: Will JA, Dawson CA, Weir EK, Buckner CK (eds) The Pulmonary Circulation in Health and Disease. Academic Press, Orlando, FL, pp 215-230

31. Hislop A, Reid L 1973 Pulmonary arterial development during childhood: branching pattern and structure. Thorax 28:129-135

32. Meyrick B, Reid L 1982 Pulmonary arterial and alveolar development in normal postnatal rat lung. Am Rev Respir Dis 125:468-473

33. Hales CA, Rouse ET, Slate JL 1978 Influence of aspirin and indomethacin on variability of alveolar hypoxic vasoconstriction. J Appl Physiol 45:33-39

34. Weir EK, McMurtry IF, Tucker A, Reeves JT, Grover RF 1976 Prostaglandin synthetase inhibitors do not decrease hypoxic pulmonary vasoconstriction. J Appl Physiol 41:714-718

35. Gerber JG, Voelkel N, Nies AS, McMurtry IF, Reeves JT 1980 Moderation of hypoxic vasoconstriction by infused arachidonic acid: role of $\mathrm{PGI}_{2}$. J Appl Physiol 49:107-112

36. Tod ML, Cassin S 1984 Perinatal pulmonary responses to arachidonic acid during normoxia and hypoxia. J Appl Physiol 57:977-983

37. Leffler CW, Tyler TL, Cassin S 1979 Responses of pulmonary and systemic circulations of perinatal goats to prostaglandin $\mathrm{F}_{2 \alpha}$. Can J Physiol Pharmacol 57:167-173

38. Kuehl FA, Dougherty HW, Ham EA 1984 Interactions between prostaglandins and leukotrienes. Biochem Pharmacol 33:1-5

39. Yokochi K, Olley PM, Sideris E, Hamilton F, Huhtanen D, Coceani F 1982 Leukotriene $\mathrm{D}_{4}$ : a potent vasoconstrictor of the pulmonary and systemic circulations in the newborn lamb. In: Samuelsson B, Paoletti R (eds) Leukotrienes and Other Lipoxygenase Products. Raven Press, New York, pp 211-214

40. Kadowitz PJ, Hyman AL 1984 Analysis of responses to leukotriene $D_{4}$ in the pulmonary vascular bed. Circ Res 55:707-717

41. Meyrick B, Niedermeyer ME, Ogletree ML, Brigham KL 1985 Pulmonary hypertension and increased vasoreactivity caused by repeated indomethacin in sheep. J Appl Physiol 59:443-452

42. Flower R 1974 Drugs which inhibit prostaglandin biosynthesis. Pharmacol Rev 26:33-67

43. Piper P, Vane J 1969 Release of additional factors in anaphylaxis and its antagonism by anti-inflammatory drugs. Nature 223:29-37 